\title{
Structure-Char Forming Relationship in Intumescent Fire Retardant Systems
}

\author{
G. BERTELLI \\ Himont Italia S.r.I. \\ Centro Richerche "G. Natta" \\ P. Ie Donegani 12, 44100 Ferrara, Italy \\ P. GOBERTI and E. MARCHETTI \\ Himont Italia S.r.l. \\ Centro Richerche "G. Natta" \\ $P$. le Donegani 12,44100 Ferrara, italy
}

\author{
G. CAMINO \\ Dipartimento di Chimica Inorganica, \\ Chimica Fisica e Chimica dei Materiali dell'Università \\ Via P. Giuria 7, 10125 Torino, Italy
}

\author{
M. P. LUDA DI CORTEMIGLIA and L. COSTA \\ Dipartimento di Chimica Inorganica. \\ Chimica Fisica e Chimica dei Materiali dell'Università \\ Via P. Giuria 7, 10125 Torino, Italy
}

\begin{abstract}
A systematic study of the intumescent process occurring on heating mixtures of char-forming nitrogen containing compounds with ammonium polyphosphate, is undertaken. Preliminary results show that the chemical structure strongly affects the char yield of the char-forming compounds. Furthermore, chemical reactions take place on heating them in mixture with ammonium polyphosphate, which may modifie their char yield. The structure of the intumescent char is shown to depend on the chemical structure of the char-forming component and on whether the char is formed on heating the ammonium polyphosphate/char-forming mixture alone or within the polymer matrix.
\end{abstract}

KEYWORDS: fire retardants, intumescent additives.

\section{INTRODUCTION}

The awareness of fire hazard due to formation of obscuring, toxic and corrosive smoke evolved during combustion of polymeric materials, has recently increased the interest for halogen-free fire retardant systems. Indeed, the high effectiveness of traditional halogen-based additives, in decreasing ease of ignition and rate of flame spread, has to be balanced against the formation of toxic, corrosive, optically dense smoke on heating of halogen and metal halides [1].

Among halogen-free fire retardants, the so called intumescent systems seem to provide a satisfactory solution in terms of minimisation of overall fire hazard $[2,3]$. Their action is based on the formation of a multicellular charred layer on the surface of the material when heated, which protects it from the further action of the flame. However, the mechanism of intumescence is still poorly understood and the presently available commercial systems are characterised by an effectiveness which is too low to supply a general solution to fire retardance of polymeric materials.

We have undertaken a systematic study of typical intumescent systems with the purpose of understanding the key factors in their fire retardant action. This should provide the elements for designing of new more effective systems. Preliminary results are reported here concerning the effect of the chemical structure of the char-forming additive on the yicld of char and on its characteristics. The typical charring "catalyst" ammonium polyphosphate was used in combination with the char-forming additive. 


\section{MATERIALS AND METHODS.}

\section{Materials.}

Ammonium polyphosphate (APP) was the high molecular weight polymer Exolit 422 by Hoechst:

$$
\mathrm{NH}_{4}-0\left[\begin{array}{l}
0 \\
\| \\
\mathrm{P}-0 \\
1 \\
0 \\
1 \\
\mathrm{NH}_{4}
\end{array}\right]_{\mathrm{n}} \mathrm{NH}_{4}
$$

The following nitrogen containing polymers were used as char-forming additives:

1. Melamine-formaldehyde polycondensate (L140) by Ausind

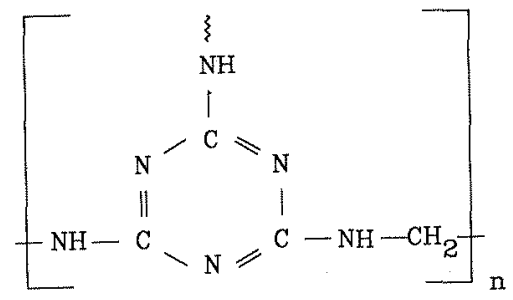

2. Melamine-ethyleneurea-formaldehyde polycondensate $(E F-3)$ by Himont

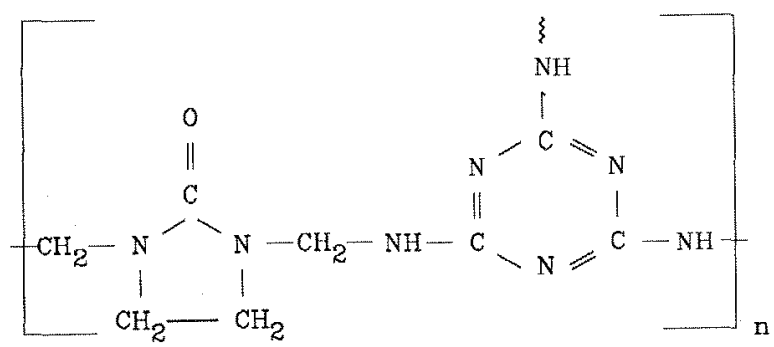

3. Ethyleneurea-formaldehyde polycondensate (PEU) by Montefluos

$$
\left[\begin{array}{ccc} 
& 0 \\
& & \\
& \mathrm{C} & \\
-\mathrm{CH}_{2}-\mathrm{N} & \mathrm{N} \\
1 & 1 \\
\mathrm{CH}_{2}-\mathrm{CH}_{2}
\end{array}\right]_{\mathrm{n}}
$$




$$
\left[\mathrm{N} \underset{\mathrm{CH}}{-\mathrm{CH}_{2}-\mathrm{CH}_{2}-\mathrm{N}-\mathrm{CO}}\right]_{\mathrm{n}}^{-\mathrm{CH}_{2}}
$$
mortar.

Mixtures of APP with the char-forming additives were prepared by grinding in a

Polypropylene (PP) was supplied by Himont and added with APP/char-forming mixtures, in a Brabender AEV 330.

Thermal Treatments.

The "char" yield is defined as the yield of residue obtained by heating the charforming additives, either alone or in mixture with APP (APP/additive $=2: 1$ by wt, sample $2 \mathrm{~g}$ ) at $400^{\circ} \mathrm{C}$ in air, to constant weight loss. The char was cooled in nitrogen and dried in desiccator prior to weighing. The thermal resistance of the char was evaluated by heating at selected temperatures for $30 \mathrm{~min}$ (e.g. $500,600,700,800^{\circ} \mathrm{C}$ ). In the case of mixtures with APP, the residue obtained at $400^{\circ} \mathrm{C}$ was extracted with boiling water in a Soxhlet to constant weight $(8 \mathrm{hr})$ to obtain the yicld of the water insoluble char.

The content of $\mathrm{C}, \mathrm{H}, \mathrm{N}$ and $\mathrm{P}$, was evaluated in the chars by standard elemental analysis techniques.

\section{Char Structure.}

The structure of chars obtained on heating the mixtures of APP with the char-forming additive (2:1) either alone or at overall $70 \%$ concentration in $\mathrm{PP}$, at $500^{\circ} \mathrm{C}$ in air, was examined by scanning electron microscopy (SEM) and microanalysis by energy dispersive system (EDS) carried out on Philips SEM 515 and EDAX 9900 respectively. The software HAX and windowless detector ECON were used for quantitative evaluations. Chars produced in the absence of polymer were treated $2 \mathrm{hr}$ in boiling water to avoid instrument contamination by phosphorus moieties.

Oxygen Index Test.

The test was carried out in a Stanton Redcroft instrument, following ASTM D 2863-77. Samples of the char formed on the top of fire retarded PP specimens, burned to self-extinguishment at oxygen concentration equal to their oxygen index (combustion char), were examined by SEM and EDS.

Foaming Behaviour.

The increase of volume of the fire retardant system (mixture of char-forming additive with APP) either pure or in PP matrix, was measured as a function of temperature, on samples heated at $20^{\circ} \mathrm{C} / \mathrm{min}$ with a method previously described [4].

\section{RESULTS AND DISCUSSION}

Char Yield and Thermal Resistance.

The char yield is highest from L140 $(60 \%)$ and it decreases to 40,25 and $20 \%$ respectively in the case of EF-3, PEU and PCP (Figure 1). The time for complete charring 


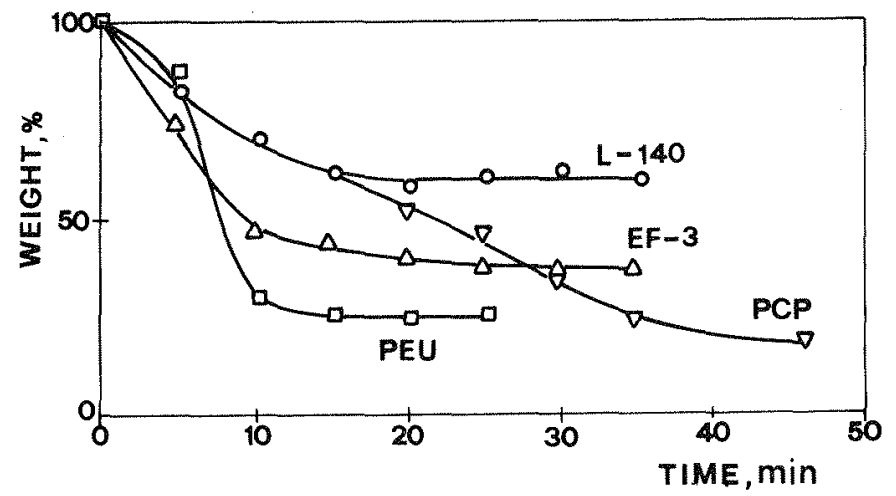

FIGURE 1. Weight loss of the char-forming compounds heated at $400^{\circ} \mathrm{C}$ in air.

at $400^{\circ} \mathrm{C}$ is similar for $\mathrm{L} 140, \mathrm{EF}-3$ and PEU $(10-15 \mathrm{~min})$, whereas it is longer for PCP (40-50 min). Nitrogen is an important component of the chars, representing the 20 $50 \%$ by weight, as shown by elemental analysis data of table 1 .

TABLE 1. Elemental analysis data of chars of figure 1.

$\begin{array}{lccc}\text { Compound } & \mathrm{C} \% & \mathrm{H} \% & \mathrm{~N} \% \\ \text { L140 } & 40.08 & 2.86 & 52.75 \\ \text { EF-3 } & 50.81 & 3.89 & 40.06 \\ \text { PEU } & 63.72 & 4.40 & 21.75 \\ \text { PCP } & 56.51 & 1.52 & 29.51\end{array}$

The $\mathrm{C} / \mathrm{N}$ molar ratios in the original compound and in the char are compared in figure 2. It can be seen that the $\mathrm{C} / \mathrm{N}$ ratio of $\mathrm{L} 140, \mathrm{EF}-3$ and $\mathrm{PCP}$ is not sensibly changed on heating. Whereas, in the case of PEU, a relevant decomposition of the cyclic structure should take place on heating, with volatilisation of $\mathrm{N}$-rich moieties, since the ratio is strongly increased in the char.

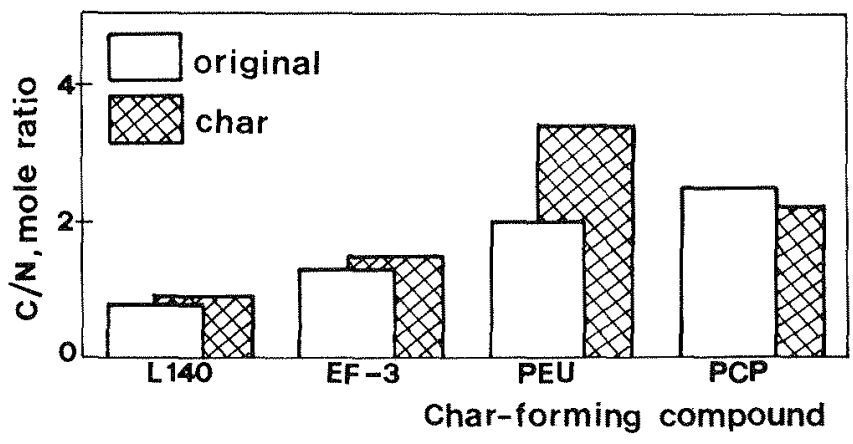

FIGURE 2. $\mathrm{C} / \mathrm{N}$ mole ratio in original compounds and in the chars of figure 1. 


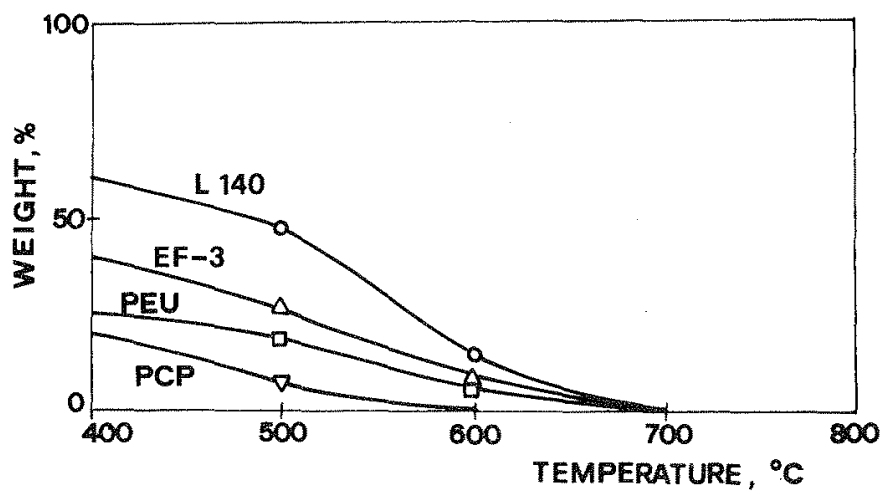

FIGURE 3. Weight loss of the chars of figure 1, heated $30 \mathrm{~min}$ in air, referred to the original compounds.

A comparable thermal resistance is shown by the chars obtained from the four compounds (Figure 3 ).

A completely different thermal behaviour is shown by the four char-forming compounds when they are heated in the presence of APP. Indeed, a comparable overall residue yield at $400^{\circ} \mathrm{C}$ is obtained from all of them, ranging from 70 to $80 \%$ (Figure 4). However, a fraction of this residue is water soluble and the real char yield from the organic component of the mixture must be calculated on the basis of the water insoluble part of the residue. Figure 5 shows indeed that a relevant decrease of char yield is induced by APP on L140 and EF-3, whereas a corresponding negligible effect is observed for PEU and PCP.

These data indicate that a chemical interaction occurs between APP and the charforming additive on heating. This interaction does not lead to extensive incorporation of $P$ in the char, since it can be calculated that more than $90 \%$ of the original $P$ of the mixture is water soluble after heating at $400^{\circ} \mathrm{C}$. The interaction is likely to give water soluble nitrogen-rich moieties (possibly including $\mathrm{P}-\mathrm{N}$ compounds) as shown by the large increase of the $\mathrm{C} / \mathrm{N}$ ratio in the insoluble part of the residue as compared to the overall

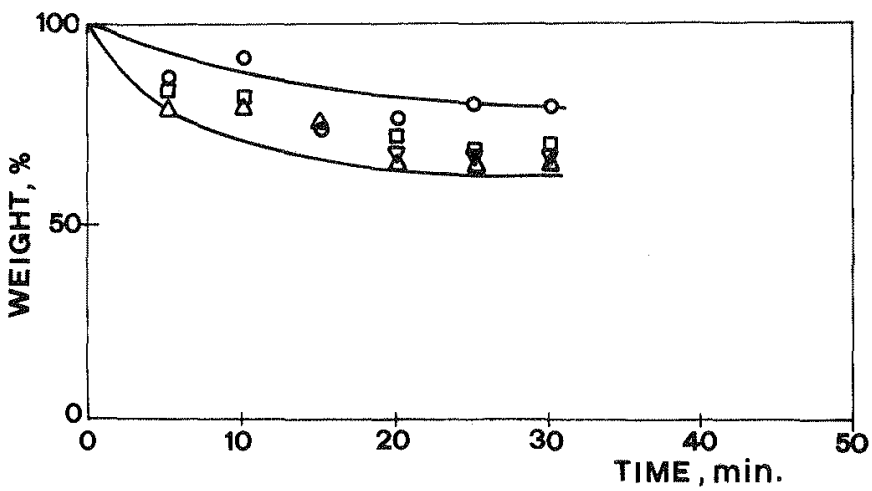

FIGURE 4. Weight loss of mixtures of APP with the char-forming compounds $(2 / 1)$ heated in air at $400^{\circ} \mathrm{C}$. Symbols as in figure 1 . 


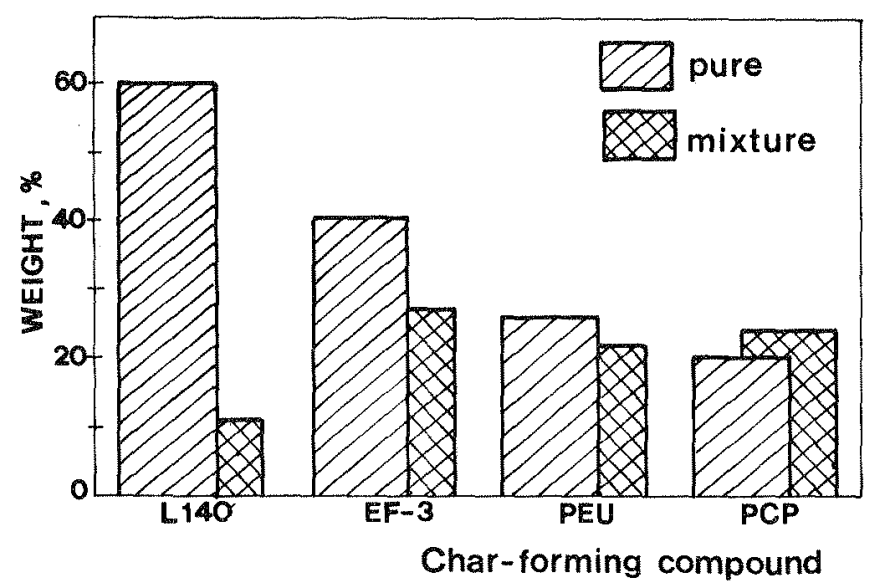

FIGURE 5. Char yield at $400^{\circ} \mathrm{C}$ from char-forming compounds heated either pure or in mixtures with APP, after water extraction.

residue and the original mixture (Figure 6). Indeed this ratio, except for the case of PEU, was almost unchanged after heating the organic compounds alone (Figure 2). A similar thermal resistance is found for the overall residue at $400^{\circ} \mathrm{C}$ from the four APP/char-forming systems, with the largest weight loss between $600-700^{\circ} \mathrm{C}$ (Figure 7) corresponding to volatilisation of polyphosphoric acid [5].

Char Characteristics.

A similar char structure was obtained on burning in the oxygen index test, PP containing $30 \%$ of mixtures of APP with char-forming compound $(2: 1)$ in the case of EF-3, PEU and PCP. For example, the SEM micrograph of figure 8a shows that the external surface of the char is smooth with some evidence of bubbles. Large voids are present underneath (figure $8 \mathrm{~b}$ ) whose walls have a cellular structure (figure $8 \mathrm{c}$ ).

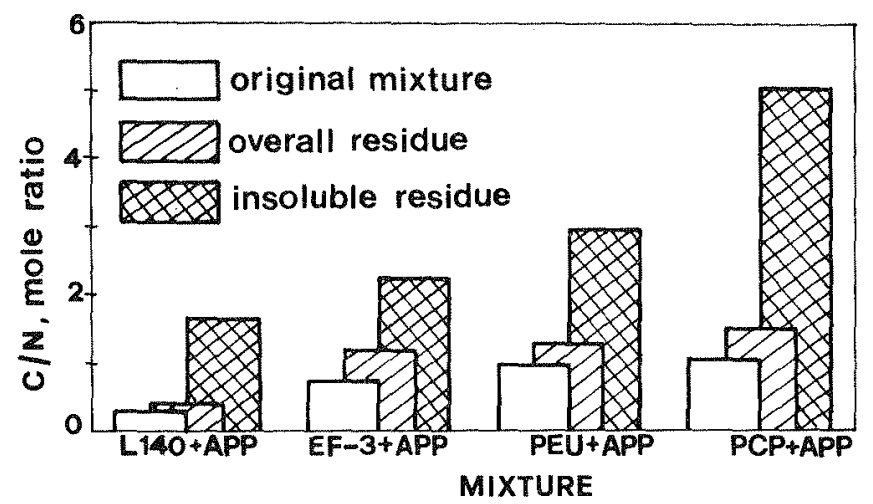

FIGURE 6. C/N mole ratio in original mixtures of Figure 4 , in the overall residue and in the insoluble fractions. 


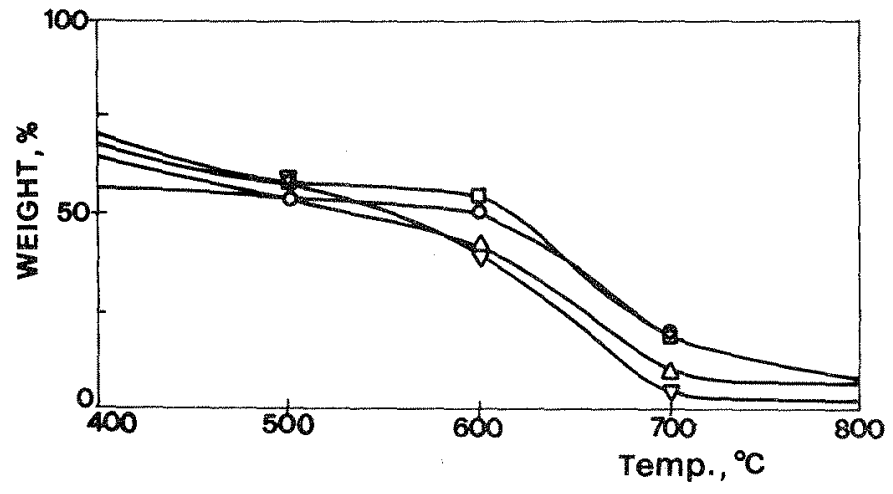

FIGURE 7. Weight loss of the residues of Figure 4, heated $30 \mathrm{~min}$ in air, referred to the original mixtures.
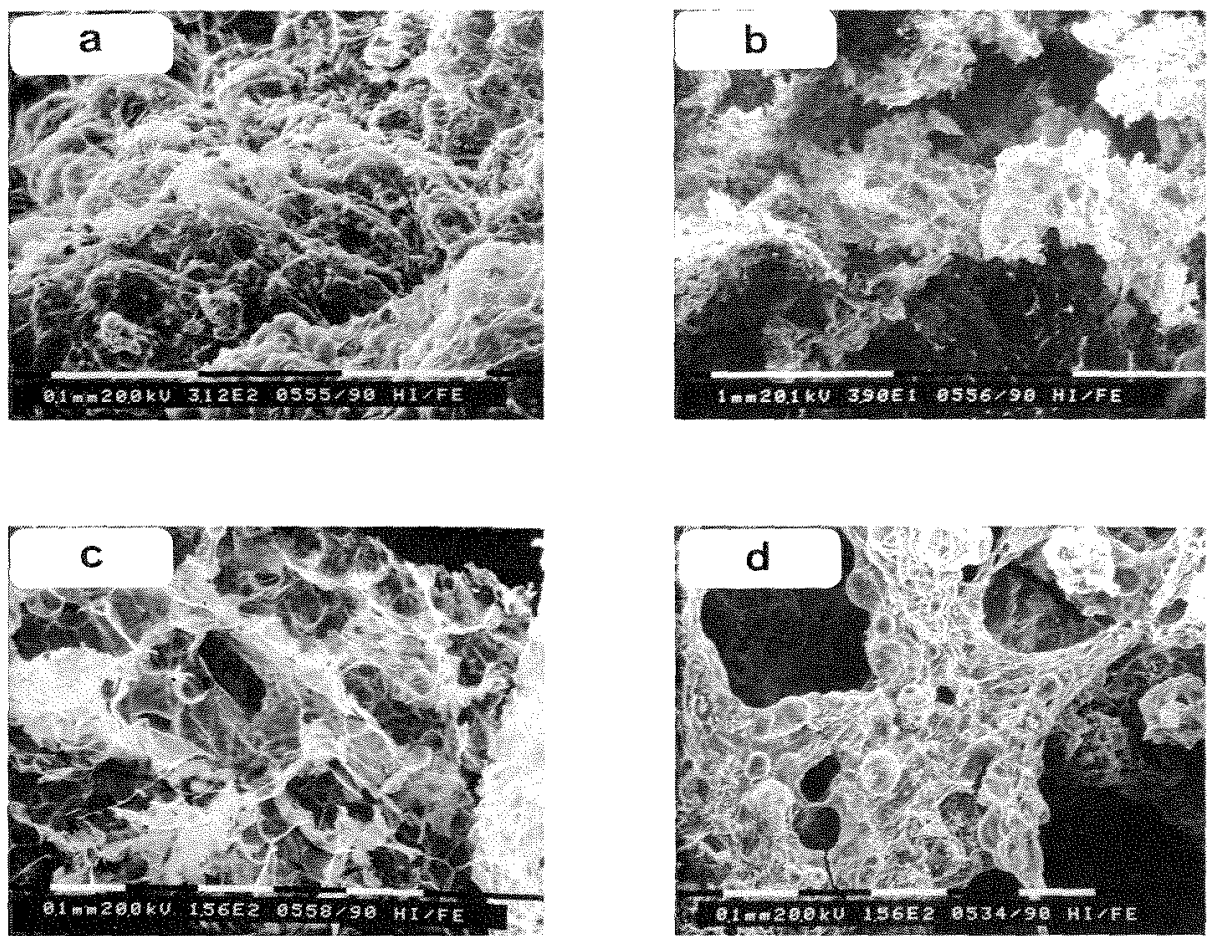

FIGURE 8. SEM micrographs of combustion chars from: PP fire retarded with APP/EF3 or L140 mixtures. EF3: outer surface x312 (a); internal structure X39 (b) and x156 (c); L140: intemal structures $\times 156$ (d). 
In the case of L140, the outer surface of the char is still similar to that of figure $8 \mathrm{a}$, whereas the walls of the voids (Figure 8d) show a more compact structure than that of the corresponding figure $8 \mathrm{c}$. This difference in structure could be responsible for the lower oxygen index value for PP added with the L140 system as compared to the others (Table 2).

TABLE 2, Oxygen index of PP containing $30 \%$ of APP/char-forming compound mixture (2:1).

Fire retardant

APP/L140

$\mathrm{APP} / \mathrm{EF}-3$

$\mathrm{APP} / \mathrm{PEU}$

APP/PCP

Oxygen index
28.5
33.4
33.0
34.2

The polymer matrix seems to play an important role in determining the characteristics of the foamed char, although pure PP burns with negligible charring. Indeed, foamed chars obtained on heating $\mathrm{APP} / \mathrm{char}$-forming mixtures alone, at $500^{\circ} \mathrm{C}$, tend to collapse on exposure to moisture when extracted from the furnace. SEM micrographs of water extracted chars show a structure which looks as if the walls of a cellular foam were completely collapsed. Whereas the chars are scarcely affected by moisture when formed in the polymer matrix. In this last case, they show a multicellular structure similar to that of the above combustion chars.

An effect of the polymer matrix is also evident on the foaming behaviour, as shown for example in figure 9 for PEU. Foaming of the APP/PEU mixture heated alone, begins at about $320^{\circ} \mathrm{C}$ when extensive charring has already occurred. The fire retarded PP apparentiy shrinks above $240^{\circ} \mathrm{C}$ because of polymer melting affecting the measuring probe position and shows a two steps foaming. The first begins at about $280^{\circ} \mathrm{C}$, before charring is evident and the second takes place at a temperature slightly higher than observed in the absence of the polymer. A much smaller overall foaming is measured in the polymer matrix, corresponding to the dilution of the intumescent additive.

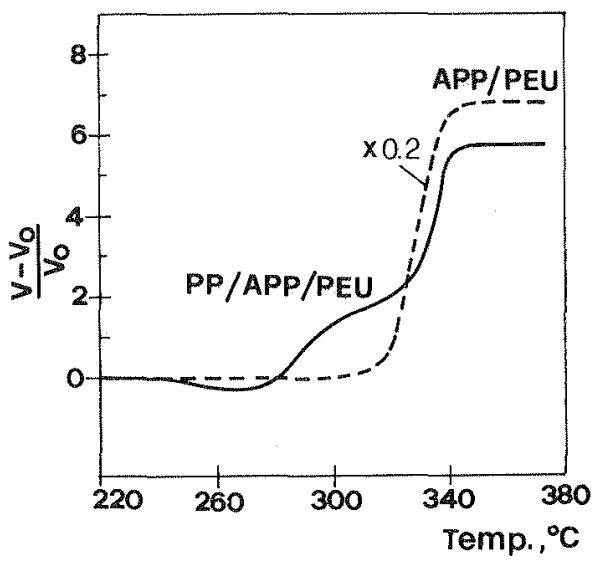

FIGURE 9. Foaming behaviour of APP/PEU 1:1 mixture heated alone or dispersed in PP matrix. Heating rate $20^{\circ} \mathrm{C} / \mathrm{min}, \mathrm{V}_{0}=$ initial volume, $V=$ Volume of foamed char. 
Moreover, we found that APP/PEU mixtures with large excess of one of the component (1:3 and 3:1) do not give measurable foaming when heated alone whereas foaming occurred upon introduction in PP. The temperature of foaming in the polymer matrix depends on the ratio APP/char-forming additive which however does not have a relevant effect on the final volume expansion.

As far as the chemical composition of the intumescent char is concerned, comparable data were found for the systems examined here. A typical output of EDS microanalysis of combustion char, referring to $\mathrm{EF}-3$, is shown in figure 10 and results are reported in table 3 .

TABLE 3. EDS microanalysis of combustion char from PP containing $30 \%$ of $2: 1$ APP/EF-3 mixture.

$\begin{array}{lllll} & \mathrm{C} \% & \mathrm{~N} \% & \mathrm{O} \% & \mathrm{P} \% \\ \text { Outer surface } & 15.1 & 11.6 & 20.0 & 53.3 \\ \text { Internal structure } & 11.7 & 15.2 & 25.3 & 47.7\end{array}$

EDS data might not be accurate because of difficulty in calibration with charred materials but they are precise and reliable for comparisons. It can be seen that the char contains a large amount of phosphorus which indicates that the phosphoricpolyphosphoric acid deriving from the thermal degradation of APP $[5,6]$, does not extensively volatilise at the combustion temperature. As a general trend, it is found that the content of $\mathrm{C}$ and $\mathrm{P}$ is larger on the surface than in the inner structure whereas the opposite holds for $\mathrm{N}$ and $\mathrm{O}$. However, in the case of phosphorus, the difference is not such to imply a preferential accumulation of phosphorus moieties on the surface.

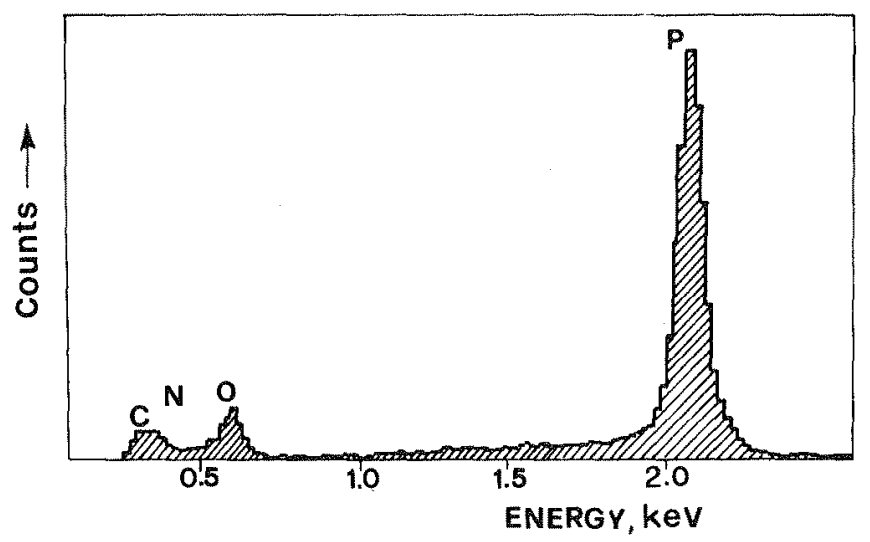

FIGURE 10. EDS microanalysis of outer surface of combustion char of Figure 8a.

\section{CONCLUSIONS}

APP and polyphosphoric acid, the pyrolysis product, can strongly modify the charring reaction of the carbon-nitrogen char-forming additives examined, depending on their chemical structure. 
The characteristics of the intumescent char depend on whether the intumescent system (APP+char-forming) is heated alone or within the polymer matrix. In the absence of polymer, the mixture of polyphosphoric acid with the char is blown to an expanded foam of poor mechanical strength which collapses on exposure to moisture. In the polymer matrix, a foamed char is obtained mostly stable to moisture in which large voids are present whose walls show a cellular structure. The chemical structure of the char-forming component may affect the char structure which could be important in terms of fire retardant effectiveness.

Work is in progress to understand chemical reactions occurring on heating polymers fire retarded with these intumescent systems, which should provide information on factors controlling the char structure and its fire retardant effectiveness.

\section{ACKNOWLEDGEMENTS}

This work was carried out with the financial support of the Progetto Finalizzato Chimica Fine II of the Consiglio Nazionale delle Ricerche.

\section{REFERENCES}

1. Cullis, C.F. and Hirschler, M.M., The Combustion of Organic Polymers, 1st ed., Clarendon Press, Oxford, 1981.

2. Camino, G. and Costa, L., "Mechanism of Intumescence in Fire Retardant Polymers", Reviews in Inorganic Chemistry, 8: 69-100, 1986.

3. Camino, G., Costa, L. and Martinasso, G., "Intumescent Fire-retardant Systems", Polymer Degradation and Stability, 23: 359-376, 1989.

4. Bertelli, G., Camino, G., Marchetti, E., Costa, L., Casorati, E. and Locatelli, R., "Parameters Affecting Fire Retardant Effectiveness in Intumescent Systems", Polymer Degradation and Stability, 25: 277--292, 1989.

5. Camino, G., Costa, L. and Trossarelli, L., "Study of the Mechanism of Intumescence in Fire Retardant Polymers: Part I - Thermal Degradation of Ammonium Polyphosphate-Pentaerythritol Mixtures", Polymer Degradation and Stability, 6: 243$252,1984$.

6. Camino, G., Grassie, N. and McNeill, I.C., "Influence of the Fire Retardant, Ammonium Polyphosphate, on the Thermal Degradation of Poly(methyl Methacrylate)", Journal of Polymer Science: Polymer Chemistry Edition, 16: 95$106(1978)$. 